\title{
La historia natural en las revistas de artesanos de México, 1840-1855
}

\author{
Rodrigo Vega y ORTEga \\ Universidad Nacional Autónoma de México \\ rodrigo.vegayortega@hotmail.com
}

Recepción: 29 enero de 2012 / Revisión: 11 de mayo de 2012

Aceptación: 7 de junio de 2012 / Publicación: diciembre de 2012

\section{RESUMEN}

La Historia natural fue una disciplina científica cuya vertiente divulgativa tuvo un espacio importante en varias revistas de México destinadas a los grupos de artesanos del país que se publicaron en los años 1840-1855. Los escritos de esta ciencia en las páginas de dichas publicaciones periódicas constituyó uno de los probables recursos que estos lectores tuvieron para instruirse informalmente en cuestiones científicas aplicadas a su vida laboral en términos botánicos, zoológicos y mineralógicos. La lectura de los escritos naturalistas tuvo entre uno de sus fines el aprovechamiento racional y pragmático de los recursos naturales del país con fines artesanales. El periodo de estudio se caracteriza por abarcar los años previos a la fundación de la Escuela de Artes y Oficios (1856) en la ciudad de México. Los escritos de las revistas para artesanos incidieron en que en dicho establecimiento educativo se impartieran formalmente y por primera vez las cátedras científicas y técnicas que requerían los jóvenes alumnos provenientes de los gremios de artesanos de varias regiones de la república.

Palabras clave: Historia natural, artesanos, revistas, México, Siglo XIX.

\section{Natural History in Mexican Trades Magazines, 1840-1855}

\begin{abstract}
The educational aspect of Natural History, as a scientific discipline, occupied an important place in various Mexican magazines intended for artisan groups, published in the years 1840-1855. The scientific articles in these magazines were one of the available resources for these readers to educate themselves informally in sciences which could be applied to their work, such as Botany, Zoology and Mineralogy. The reading of the naturalists' works had, among its aims, a rational and pragmatic use of the natural resources of the country for artisans' needs. The study period covers the years before the founding of the Escuela de Artes y Oficios (1856) in Mexico City. The articles in these trades magazines had an impact on this educational institution, as the scientific and technical subjects needed by young students from the craftsmen's guilds of the various regions of the republic, were taught formally for the first time.
\end{abstract}

Key words: Natural History, Artisans, Magazines, History of Science, Mexico, 19th-Century.

Sumario: 1. Introducción. 2. Las revistas para artesanos de México, 1840-1855. 3. Los artesanos en México, 1840-1855. 4. Historia natural para un pueblo industrioso. 5. La Historia natural y su aplicación artesanal. 6. Consideraciones finales. 7. Referencias bibliográficas. 


\section{INTRODUCCIÓN ${ }^{1}$}

A lo largo del siglo XIX la divulgación de la historia natural fue un tema recurrente en las revistas mexicanas, tanto en las publicaciones que pretendieron ser de carácter nacional como las que tuvieron un alcance local. En estas revistas existió una gama de títulos dedicados a un público amplio y otras dirigidas a sectores sociales delimitados por su edad, género o actividades laborales. Entre estas últimas resaltan las publicadas entre 1840 y 1855 que se centraron en el conjunto de artesanos del país ${ }^{2}$.

La presencia del conocimiento naturalista en las páginas de las publicaciones para artesanos constituyó uno de los recursos que posiblemente dichos lectores tuvieron para instruirse de manera informal en cuestiones científicas aplicadas a sus labores diarias. A lo largo de esta investigación se revela que este tipo de prensa tuvo entre uno de sus objetivos más importantes el aprovechamiento eficaz de las materias primas tradicionales usadas en sus oficios; el conocimiento de nuevos recursos naturales capaces de ser transformados en objetos; y en menor medida, el exhorto, por parte de los colaboradores de éstas, para que aquellos lectores con capital económico invirtieran en la transformación a gran escala de los recursos naturales del país en productos artesanales.

En estos años, la historia natural debe ser entendida como la ciencia dedicada al estudio y descripción de los tres reinos de la naturaleza: animal, vegetal y mineral. Ésta constaba de estudios anatómicos y fisiológicos; menciones del nombre vulgar y científico de los seres vivos; ciclos de vida de cada especie, junto con su utilidad económica y social; datos curiosos y propiedades médicas, entre otros aspectos, de animales y plantas; además del origen geológico y las características físico-químicas de la diversidad de minerales del mundo. Dada la extensión de las cuestiones estudiadas por los naturalistas y la amplitud de su objeto de estudio, la divulgación de este conocimiento no fue igual para todos los lectores, pues se centró en las "necesidades" que cada sector social tenía de éste. Igualmente, el interés de cada conjunto de lectores era definido por el cuerpo de redactores de cada publicación, casi todos ellos pertenecientes a la "República de las Letras". Dicho término se entendía como el grupo de hombres "sabios y eruditos" vinculados entre sí por la gama de conocimientos cultos (disciplinas científicas, humanísticas y artísticas) que fomentaban a través de proyectos colectivos que no siempre estuvieron auspiciados por el Estado mexicano. Este ámbito intelectual tuvo como base la igualdad de condiciones de sus participantes; la reunión periódica de éstos para discutir diversos temas en agrupaciones; el propósito de divulgar los conocimientos ya discutidos entre la mayor cantidad de connacionales mediante revistas y conferencias públicas; y autonombrarse como mediadores de tales conocimientos entre los grupos "iletrados" del país.

\footnotetext{
${ }^{1}$ Esta investigación recibió financiamiento del proyecto PAPIIT (IN 303810): "Naturaleza y territorio en la ciencia mexicana (1768-1914)" del Instituto de Geografía - UNAM y DGAPA - UNAM, responsable Dra. Luz Fernanda Azuela.

2 Los artesanos en el siglo XIX formaban un grupo amplio de oficios organizados en gremios que poseían medios de producción y conocimientos técnicos para elaborar objetos que la sociedad consumía. La jerarquía de cada taller estaba conformada por los propietarios que en varias ocasiones eran los maestros artesanos, junto con diversos aprendices. En 1842 la heterogeneidad de actividades artesanales de la ciudad de México sumaba varias decenas que estaban repartidas en cerca de 1.500 talleres. Pérez Toledo, 1996, p. 53.
} 
Precisamente las asociaciones capitalinas desempeñaron un papel importante en el ámbito científico mexicano, ya que se convirtieron en un espacio para la convivencia de hombres de ciencia junto con empresarios, literatos y políticos reunidos en torno a cierto objetivo "patriótico", por ejemplo, la "popularización" de los saberes cultos. Entre las agrupaciones de la ciudad de México más célebres en la primera mitad del siglo XIX y que tuvieron como objetivo fomentar el desarrollo económico del país se encuentran la Junta de Industria de la ciudad de México (1841-1842), la Sociedad de Agricultura del Distrito Federal (1844), la Junta de Fomento de Artesanos (18441845), la Sociedad Filantrópica Mexicana (1848) y la Sociedad Promovedora de Mejoras Materiales (1852). Todas ellas publicaron revistas y divulgaron las ciencias naturales como se verá a continuación.

La fuente hemerográfica del período 1840-1855 contiene una riqueza cuantitativa y cualitativa que permite abordar la divulgación científica entre el público lector artesanal que, hasta el momento, cuenta con pocos estudios. Frente a los costosos libros provenientes del extranjero de esta época con temas similares, las revistas del país, menos onerosas, demuestran la relevancia y el esfuerzo emprendido por varios letrados mexicanos en pro de la instrucción de diversos grupos sociales, aunque ésta fue de tipo informal. Esta vía impresa transmitió saberes cultos de los hombres de ciencia, casi todos residentes en la capital de la República Mexicana, hacia individuos considerados iletrados por sus escasos estudios formales, pero vistos como capaces de comprender lo publicado bajo un discurso sencillo, ameno y cercano a su día a día.

Algunas de las revistas para artesanos dejan ver la relevancia que dicha divulgación tuvo entre la pluralidad de contenidos que publicaron. De entre las revistas que incluyeron cuestiones de historia natural aplicadas a las actividades de sus lectores resaltan el Semanario de la Industria Megicana. Que se Publica bajo la Protección de la Junta de Industria de esta Capital (1841-1842); El Cometa; Semanario de Política, Agricultura y Artes (1842-1843); el Semanario Artístico para la Educación y el Progreso de los Artesanos (1844-1846); El Eco del Comercio; Periódico de Literatura, Política, Artes e Industria de la Sociedad Filantrópica Mexicana (1848); La Imitación. Periódico de Literatura, Bellas Letras y Artes (1850); la Revista Mensual de la Sociedad Promovedora de Mejoras Materiales (1852); El Artista (1853-1854); y El Heraldo; Periódico Político, Industrial, Agrícola, Mercantil, de Literatura y Artes $(1855)^{3}$. En las décadas de 1860 y 1870 se multiplicaron los títulos de la prensa de artesanos, especialmente los auspiciados por grupos políticos, por ejemplo, El Amigo del Pueblo (1869), El Socialista (1871-1888), La Huelga (1875), El Hijo del Trabajo (1876-1884) y La Voz del Obrero (1878) ${ }^{4}$.

A decir de Martin Lyons, durante la primera mitad del siglo XIX entre los lectores europeos figuraban "las clases medias y bajas, a los aprendices de artesanos y a los trabajadores de cuello duro que en todas partes pasaron a engrosar la clientela de la bibliotecas de préstamo" y de los impresos periódicos ${ }^{5}$. Un texto clásico sobre la re-

\footnotetext{
3 Cabe aclarar que estas revistas fueron consultadas en el Fondo Reservado de la Hemeroteca Nacional de México.

4 Santos y González, 2005, p. 165.

5 Lyons, 2006, p. 502. Los redactores de las revistas mexicanas se inspiraron en algunos modelos editoriales de la prensa extranjera dedicada a temas artesanales como The Mechanics'Magazine and Journal
} 
lación entre artesanos y lectura en la Inglaterra calcula que entre 1800 y 1860 más de dos tercios de los artesanos de este país sabían leer y consumían algún tipo de lectura, entre ella la científico-tecnológica ${ }^{6}$. Aunque la República Mexicana a la mitad de la centuria no tuvo condiciones sociales idénticas a las de Inglaterra, es de presumir que un número suficiente de artesanos mexicanos leyó la prensa. Probablemente, el público "iletrado" que leyó asiduamente estas revistas estuvo conformado por dueños de establecimientos artesanales, maestros artesanos y algunos trabajadores.

Entre los motivos que tuvieron los redactores de estas revistas estuvo dar a conocer la diversidad de riquezas naturales del territorio patrio dispuesta a ser aprovechada económicamente por parte de los artesanos; brindar un ejemplo de los frutos alcanzados en otros países mediante la utilización de la naturaleza local; y sugerir a los lectores el uso de especies extranjeras que fueran de fácil aplicación en México con fines artesanales. Lo anterior tuvo un contexto económico muy claro, pues desde $1821 \mathrm{el}$ país se vio "invadido" de productos europeos y estadounidense que competían fuertemente por ganar el mercado nacional, como se verá más adelante.

El periodo de estudio está acotado entre 1840 y 1855 por dos razones. La primera radica en que entre 1839 y 1850, el Boletín de la Sociedad Mexicana de Geografia y Estadística (BSMGE), primera publicación periódica de carácter científico del país, dejó de publicarse y los hombres de ciencia buscaron otros espacios impresos no académicos para dar a conocer sus escritos. En segundo lugar, la pertinencia de abarcar el primer lustro de la década de 1850 se encuentra en que son los años que antecedieron a la fundación de la Escuela de Artes y Oficios (EAO) en 1856, ubicada en las inmediaciones de la ciudad de México bajo el gobierno de Ignacio Comonfort. En este establecimiento educativo se impartieron por primera vez y de manera regular los estudios sobre cuestiones técnicas con la finalidad de instruir a los artesanos. A partir de entonces inició el proceso de formalización de la instrucción técnica del país. Potencialmente las revistas para artesanos del periodo de estudio coadyuvaron al desarrollo de la opinión pública favorable a la erección de dicha escuela.

Aunque han sido numerosos los historiadores que se han acercado a las revistas de la primera mitad del siglo XIX, por ejemplo, Laura Suárez, José Ortiz Monasterio y Brian Connaughton, ninguno de ellos ha abordado los contenidos científicos presentes en la prensa decimonónica de México, por lo cual se conoce poco de este rubro cultural ${ }^{7}$.

Entre quienes han desarrollado amplios trabajos históricos acerca de los grupos de artesanos de las ciudades mexicanas a lo largo del siglo XIX destacan Sonia Pérez Toledo, Mario Trujillo, Isnardo Santos y Carlos Illades ${ }^{8}$. Las distintas investigaciones se han centrado en la vida de los trabajadores, tomando en cuenta la situación laboral, la difusión de las ideas sociopolíticas en la prensa, el asociacionismo gremial y la

\footnotetext{
of Science, Arts, and Manufactures (Londres, 1823), The Mechanic's Union of Trade Associations (Filadelfia, 1827), The Mechanic's Free Press (Filadelfia, 1828-1831), Le Protecteur. Journal de la Société Centrale d'Encouragement des Sciences, des Arts et de l'Industrie Nationale (París, 1836-1838) y el Semanario de la Industria y Revista de Intereses Materiales (Madrid, 1846-1848).

6 WeBb, 1955, p. 2.

7 Véase Connaughton, 2003; Ortiz Monasterio, 2005; y SuÁrez, 2005.

8 Véase Pérez Toledo, 1996, 2003 y 2004; Trujillo, 1997; Illades, 2004; y Santos - GonzÁlez, 2005.
} 
relación con la élite económica, sin abordar plenamente la presencia de contenidos científicos.

En otras latitudes los estudios históricos sobre la divulgación científica y los distintos públicos consumidores de escritos científicos llevan una larga tradición, como se puede comprobar en los estudios de Robert Webb, Javier Ordóñez, Alberto Elena, Nick Jardine, James Secord, Emma Spary, Aileen Fyfe, Bernard Lightman, entre muchos otros $^{9}$. Sin embargo, en México aún son escasas las investigaciones al respecto, posiblemente porque la historiografía de la ciencia mexicana ha centrado su mirada en la relación ciencia-Estado, ciencia-élite política y ciencia-nación, especialmente en el último tercio de los siglos XVIII y XIX. Además, esta historiografía ha considerado a las primeras cuatro décadas de vida independiente como adversas al desarrollo científico por la inestabilidad política, la crisis económica, las continuas luchas civiles y la guerra con Estados Unidos. También ha afirmado que los esfuerzos popularizadores de la ciencia quedaron como meras ideas ante la falta de apoyo estatal ${ }^{10}$. No obstante, algunos de los estudios más recientes sobre la ciencia mexicana han insistido en la necesidad de abordar los medios de la divulgación científica mexicana en el siglo XIX, pues éstos estuvieron presentes a pesar de los procesos históricos que reiteradamente señalan los historiadores políticos. Entre estos estudios despuntan los trabajos de Luz Fernanda Azuela, Alejandro García Luna, Lucero Morelos, Sofía González y Susana Esparza ${ }^{11}$. En el mismo sentido, estos autores han enfatizado que los proyectos científicos mexicanos en varias ocasiones mantuvieron un intenso diálogo con las tendencias europeas y estadounidenses a pesar de la problemática nacional, como el caso de la divulgación presente en las revistas ${ }^{12}$.

Esta investigación también se propone contribuir a los escasos estudios sobre la historia de la educación informal en México, especialmente en el siglo XIX, ya que aún falta mucho para entender la presencia de diversos conocimientos fuera de las aulas, sobre todo, a través de manuales, folletos, cartillas, revistas, etcétera; pues muchos hombres y mujeres se consideraron autodidactas en varias materias. En efecto, a partir de que un impreso se da a conocer, éste "se convierte en propiedad pública, y el público lo recibe" desde su circunstancia. Conocer la recepción "es una de las más altas tareas de los historiadores, a fin de poder entenderla"13, en este caso, cómo fueron acogidos los medios de comunicación que incluyeron la divulgación científica entre los artesanos del a ciudad de México.

Los contenidos naturalistas de las revistas señaladas son profusos y varían en cada publicación, por ello se pretende analizar una muestra representativa. El número de escritos que hacen referencia a la importancia de la historia natural para los artesanos mexicanos es el siguiente:

9 Véase Webb, 1955; Ordoñez - Elena, 1990; Jardine - Secord - Spary, 2000; y Fyfe - Ligthman, 2007.

10 Esta cuestión historiográfica ha sido abordada recientemente por GUEVARA, 2009.

11 Véase GonzÁlez, 2010; Azuela - Vega y Ortega, 2011; y García Luna - Morelos, 2011.

12 Véase Connaughton, 2006.

13 Vodicka, 1989, p. 55. 
Cuadro 1. Escritos de historia natural en revistas para artesanos

\begin{tabular}{|l|c|}
\hline Título de la revista & $\mathrm{N}^{\circ}$ de escritos \\
\hline Semanario de la Industria Megicana & 24 \\
\hline El Cometa & 9 \\
\hline Semanario Artístico & 15 \\
\hline El Eco del Comercio & 11 \\
\hline La Imitación & 18 \\
\hline Revista Mensual & 35 \\
\hline El Artista & 9 \\
\hline El Heraldo & 7 \\
\hline
\end{tabular}

El total de artículos es de 128, de los cuales se empleó una muestra del 10\% (12 artículos) para elaborar esta investigación que abarcara los temas botánico, zoológico y mineralógico. Estas cifras no contemplan otras disciplinas científicas presentes en las revistas, por ejemplo: Química, Física, Matemáticas, Higiene, Geografía y aspectos tecnológicos ${ }^{14}$.

\section{LAS REVISTAS PARA ARTESANOS DE MÉXICO, 1840-1855}

En las décadas de 1840 y 1850 vieron la luz varias revistas mexicanas dirigidas a todo tipo de público, entre los cuales los artesanos no fueron la excepción. La demanda de impresos periódicos tuvo como base el crecimiento poblacional del país tras el desplome demográfico de la revolución de Independencia; la ampliación cuantitativa de la alfabetización entre los mexicanos, sin que ésta pueda considerarse masiva; el establecimiento de varias imprentas en las distintas capitales estatales, además de algunas ciudades de importancia comercial; y la buena reputación que las revistas tuvieron en dichos años como vías de instrucción informal de todo tipo de conocimientos letrados al alcance del gran público.

La generalidad de las revistas, tanto dedicadas a todo público como a estudiantes, mujeres o artesanos presentó como línea editorial el carácter misceláneo. Así, estos últimos lectores encontraron una diversidad temática compuesta por narraciones literarias cercanas a sus actividades laborales, biografías de inventores célebres, política nacional e internacional referente al artesanado, discursos sobre las bondades de la instrucción, estadísticas de producciones europeas, literatura de viaje que enfatizaba los avances de gremios artesanales de otras partes del mundo, recomendaciones laborales, reglas morales de comportamiento y divulgación científica. Particularmente, los artículos naturalistas provinieron de autores nacionales y extranjeros. Al respecto, Charles Knight señala para Europa que las revistas fueron el vehículo para comunicar a la opinión pública todo tipo de opiniones (incluidas las científicas) y fueron el me-

14 Algunos ejemplos de escritos geográficos que se encuentra en la Revista Mensual... son "Memoria sobre el puerto de Manzanillo" e "Istmo de Tehuantepec"; en La Imitación se publicaron temas matemáticos como "Curso elemental de Geometría y Mecánica aplicada a las Artes” y en el ámbito médico destaca el escrito titulado "Circulación de la sangre". 
dio en el cual "el académico retirado o el ciudadano activo podían inscribir sus teorías o sus observaciones, en un estilo familiar y sin pretensiones" para su generación y el futuro ${ }^{15}$.

En México como en las naciones europeas, los hombres cultos se erigieron como los mejores preceptores de los gremios artesanales del país y consideraron que eran los más capacitados para llevarles, mediante las revistas, conocimientos modernos y útiles para su vida. De esta manera se estableció una relación unidireccional entre redactores y articulistas hacia los lectores, pues los primeros asumieron su papel de "sabios" y consideraron que los segundos eran "incultos". Esta misma élite letrada utilizó la prensa para "mejorar" las costumbres sociales y prácticas laborales de los grupos artesanales mediante una imposición de hábitos laborales "modernos" a la altura de Europa occidental, como puntualidad, disciplina, asistencia continua e individualismo ${ }^{16}$.

También a mediados de siglo en varios países de Europa y América las élites cultas promovieron la creación de bibliotecas populares para atraer a la lectura a colectivos sociales que se les consideraba alejados de la cultura. "Estaban destinadas al pueblo, a las capas populares compuestas de artesanos, tenderos y trabajadores asalariados", así como a estudiantes. En estas bibliotecas los lectores tenían a la mano libros y revistas que no podían comprar, a la vez que facilitaban "cultura y distracción a mayores y pequeños, aparte de capacitar mejor profesionalmente a los adultos y de forma a los estudiantes" 17 .

La demanda de revistas varió a lo largo de la República mexicana, ya que en la capital era más fácil comprarlas que en los poblados pequeños. Cada número valía alrededor de dos a tres reales, lo que sumaba entre dos y cuatro pesos por tomo, dependiendo de la revista. Cada una de ellas se conseguían en imprentas, alacenas, librerías y cafés o pagando por adelantado al suscribirse ${ }^{18}$. Este costo representaba cierto gasto del lector, por lo que presumiblemente muchos de ellos recurrieron al préstamo por parte de colegas del trabajo, dueños de talleres, amigos y familiares. Asimismo, la lectura en voz alta permitió que el conocimiento albergado en la prensa llegara a mayor número de lectores-escuchas con respecto a sólo lectores ${ }^{19}$. Lo anterior se complementó mediante una escritura de artículos científicos basada en una narración acorde con el grado de instrucción del lector potencial y un vocabulario sencillo.

Para atraer un nutrido público, tanto articulistas como redactores escribieron sobre la gran utilidad que traería la lectura de los contenidos, especialmente al aprovechar algunas de las horas libres de cada día, pues era preferible instruirse que desperdiciar el tiempo en vicios. Este proyecto de acercar la cultura científico-técnica al artesanado mexicano es similar al que la Real Sociedad Económica Matritense emprendió a principios del siglo XIX a través de la fundación de escuelas y la publicación de impresos para artesanos españoles ${ }^{20}$.

15 KNIGHT, 2007, p. 152.

16 Pérez Toledo, 2003, p. 313.

17 Sánchez García - Martínez, 2010, p. 49.

18 SuÁrez, 2005, p. 85.

19 Sobre las prácticas de lectura entre el artesanado francés véase AGULHON, 1994.

20 Negrín, 2009, p. 440. 
La prensa destinada al artesanado mexicano se constituyó en uno de los medios de instrucción informal que los letrados del país echaron a andar a mediados del siglo XIX. Para ello contó con "aliados" como los redactores y un nutrido grupo de articulistas interesados en "modernizar" a los iletrados del país bajo la óptica de que el conocimiento más vanguardista era el científico. Pero esto no se llevó a cabo desde una perspectiva especulativa, sino bajo su practicidad, es decir, la aplicación en las actividades laborales de cada uno de los grupos de lectores. Por ello, estos impresos tuvieron como cometido la divulgación de temas útiles al progreso de la nación, dejando de lado el lenguaje académico. Efectivamente, la presencia del conocimiento más allá de su ámbito especializado estuvo marcada por el uso de un lenguaje cercano a los lectores. No hay que olvidar que algunas de las revistas para artesanos fueron órgano de las mencionadas agrupaciones vinculadas con este sector económico a tono con las actividades "cultas" de otras agrupaciones.

Particularmente, el artesanado fue visto como un grupo laboral capaz de recibir el "progreso" científico promovido a través de empresas letradas que incorporaron este conocimiento en sus faenas diarias, sobre todo los maestros artesanos. Así, este grupo lector interesó a la élite cultural, al menos de la ciudad de México, como destinatario de la cultura letrada divulgativa, es decir, el traslado de la ciencia hasta sus hogares o talleres. Lo anterior se debió a que el país carecía de una escuela de instrucción superior, como la futura $\mathrm{EAO}$, que adiestrara a los jóvenes artesanos en la más moderna práctica científico-técnica a la usanza de varias naciones de Europa.

En estas revistas se vio la manera de instruir a los artesanos mediante un "mentor" que escribía los artículos y les proporcionaba los más variados conocimientos por medio de escritos sencillos y por entregas, teniendo como meta cultivarlos e incitarlos a innovar en cuanto a eficiencia en el aprovechamiento de las materias primas y aplicación de las especies naturales en sus oficios. Los hombres de letras comprendieron que la nación requería de individuos preparados para desarrollarlo económicamente, en donde los "técnicos del país" ocuparían un lugar destacado. Paulatinamente en las décadas de 1840 y 1850 el conocimiento científico, en tanto que expresión de la cultura letrada, dejó de ser patrimonio exclusivo de la élite e incursionó en nuevos públicos, entre ellos el artesanado, que permitió a la ciencia mexicana ampliar sus redes de influencia social.

\section{LOS ARTESANOS EN MÉXICO, 1840-1855}

Después de la revolución de Independencia, la economía mexicana se desplomó alarmantemente, pues la contracción de la explotación minera, el abandono de los cultivos por parte de cientos de campesinos, el cierre de numerosos talleres artesanales, el estancamiento del comercio con España y la fuga de capital generaron restricción monetaria y un escenario propicio para los problemas sociales ${ }^{21}$. Lentamente se pusieron en marcha todas estas actividades, con lo que la recuperación del país fue posible hacia la segunda mitad de la década de 1830 y se mantuvo hasta 1855 .

21 CÁrdenas, 1999, p. 84. 
En la mencionada reactivación, el artesanado mexicano desempeñó un papel esencial, pues se encontraba repartido en toda la república a través de los distintos poblados urbanos y semi-urbanos. Si bien en los años 1840-1855 no puede considerarse mayoritario en cuanto al total de la población del país, sí representaba una diversidad de grupos laboralmente activos. Por ejemplo, de acuerdo con los estudios de Sonia Pérez Toledo, en el padrón de 1842 de la ciudad de México se contabilizaron 11.229 artesanos en las distintas ramas productivas que constituyeron poco más del $9 \%$ del total de los habitantes y casi el $30 \%$ de la población de trabajadores activos en ésta, lo que da una idea del público lector potencial de las revistas al despuntar la década ${ }^{22}$. En cuanto a las otras ciudades, la proporción fue similar, en Puebla, Guanajuato, Guadalajara, Orizaba, San Luis Potosí, León, Morelia, Oaxaca, Querétaro o los poblados de los Altos de Jalisco presentes en las listas de suscriptores.

Precisamente en el lapso de tiempo comprendido entre 1840-1855 el artesanado mexicano tuvo un intenso desarrollo que no encontró paralelo en el contexto latinoamericano. Sin embargo, la amplia competencia de los productos nacionales contra las importaciones fue un obstáculo en el crecimiento, a la vez que un aliciente para su fomento como se verá más adelante ${ }^{23}$. En esta época en los talleres se elaboraban y vendían productos de todo tipo, como objetos de cera, orfebrería y cerámica, hilados de algodón y seda, lana para paños, fibras de cáñamo y lino, objetos de vidrio y porcelana, ladrillos, tabaco, comestibles como harinas, dulces y pan, instrumentos de diversos metales y hojas de papel ${ }^{24}$. Todo ello en franca competencia con los productos extranjeros que en ocasiones eran de mejor calidad y menor precio. Aunque este ámbito laboral hubo una diversidad de rangos de edad, pues laboraban adultos al lado de adolescentes y personas maduras.

Diversos historiadores económicos señalan que en varias regiones de México se fomentó ampliamente la modernización de los gremios artesanales desde el final de la década de 1830, cuando se instalaron algunos talleres que contaban con hilado de algodón mecanizado ${ }^{25}$. En el periodo 1840-1855 el número de hiladoras mecánicas pasó de 125.362 en 1843 a 135.538 a 1851 y en 1854 sumaron 145.768. Este aumento cuantitativo tuvo como base la proliferación de estos talleres en el noreste y lugares tan distantes del centro como Colima y Durango. En estos mismos años, la modernización también abarcó la fabricación de vidrio, acero, ladrillos, paños de lana, porcelana, maderas finas y harina, a tono con las importaciones ${ }^{26}$. Posiblemente los empleados de estos talleres fueron lectores potenciales de las revistas, especialmente los maestros artesanos.

Probablemente a los asalariados de talleres les resultara difícil tener acceso directo a las revistas debido al alto porcentaje de analfabetismo, las largas jornadas de trabajo, los bajos salarios y las deficientes condiciones laborales. No hay que olvidar que la lectura en voz alta desempeñó un papel determinante en la difusión de los contenidos publicados, pues en las horas de descanso, los días festivos u otros momentos sin

22 Pérez Toledo, 1996, p. 134.

23 Bernecker, 1999, p. 116.

24 Pérez Toledo, 2004, pp. 180-181.

25 Plana, 2004, p. 37.

26 Corona, 2004, p. 88. 
actividad laboral, estos individuos pudieron juntarse a escuchar la lectura de uno de ellos. Asimismo, los dueños de los talleres también pudieron llevar a cabo una lectura en voz alta en reuniones colectivas en ámbitos alejados del trabajo ${ }^{27}$.

En cuanto a los artesanos como lectores de las revistas mexicanas, a principios de la década de 1840 los redactores de El Cometa... enunciaron en el "Prospecto" su desinteresado compromiso por aleccionar a los lectores mediante la popularización de la gama de conocimientos cultos que años antes habían propiciado el florecimiento de los gremios artesanales europeos ${ }^{28}$. En efecto, creían firmemente que era necesario fomentar las destrezas intelectuales del público lector, como la "invención", que permitirían el desarrollo de las actividades artesanales y era base del "progreso social". Los redactores esperaban que la lectura de los artículos despertara en los artesanos el germen de la curiosidad científica mediante una multitud de ejemplos y noticias sobre adelantos técnicos en distintas ciudades del globo.

Como sucedió con las otras publicaciones dirigidas a los artesanos mexicanos, los redactores de El Artista no buscaron únicamente el aspecto académico del conocimiento científico -"árido, frío y severo"-, sino la amenidad de éste a través de la escritura sencilla e interesante, que atraería a numerosos lectores ${ }^{29}$. Particularmente, la historia natural no se presentó en ningún momento bajo su "estado grave" como en los tratados científicos, pues la estrategia fue revestirla "del traje social" propio de las revistas concebidas a pasar por "toda clase de manos". La vocación editorial de dicha revista se expresó a manera de una enciclopedia de conocimientos útiles publicada en varios fascículos numerados, enfatizando la historia natural, Farmacia, Mineralogía, Química, Agricultura, Zoología o Botánica.

En 1850 la "Introducción" de La Imitación ... revela que las iniciativas de la década anterior siguieron vigentes, pues sus redactores invitaron a la República de las Letras a participar intensamente en la gran empresa de llevar el conocimiento a los artesanos, pues mencionaron que se había invitado a los "amantes de las ciencias y del progreso" del país a que escribieran sobre los ramos científicos de su preferencia y afirmaron que en las columnas de la revista se publicarían artículos sobre ciencias y artes, "tales, que instruyendo, ilustrando y alentando" a todos los lectores involucrados en los ramos artesanales se elevaría la calidad de los productos nacionales ${ }^{30}$.

No sólo las declaraciones de intención de los redactores de las revistas presentadas hasta ahora expresaron los beneficios que la instrucción traería consigo entre los lectores, ya que otros letrados participaron en ese mismo debate y presentaron propuestas concretas para tal fin. Entre los numerosos escritos dedicados al fomento de la instrucción artesanal resalta el titulado "Educación Literaria", publicado en el Semanario Artístico... bajo autoría anónima. El autor señaló que era incuestionable la importancia de enseñar la gama de disciplinas científicas aplicadas a las "artes mecánicas, sin las cuales, no podría progresar ni alcanzar el grado de perfección de que eran susceptibles", teniendo en cuenta el auxilio de las ciencias físicas, naturales

27 Ortiz Monasterio, 2005, p. 62.

28 RedACtORES, 1842, p. 1.

29 RedACtORES, 1853, p. 1.

30 Redactores, 1850, p. 2. 
y matemáticas, en cuyos principios se fundaban ${ }^{31}$. Por ello, los artículos dirigidos a estos lectores debían basarse en un vocabulario sencillo y cercano a éstos bajo el respaldado de los redactores.

\section{HISTORIA NATURAL PARA UN PUEBLO INDUSTRIOSO}

Como se ha visto, el esfuerzo por divulgar el conocimiento naturalista entre los artesanos fue una empresa educativa llevada a cabo por los redactores de varias revistas de los años 1840-1855. Esto se debió al menos a tres motivos: primero, a los intentos por elevar la eficiencia del trabajo y calidad de las manufacturas hechas en México a través de técnicas provenientes de Europa y Estados Unidos, junto con el aprovechamiento de nuevas materias primas de origen mexicano como extranjero. Segundo, a que durante dichos años el gobierno mexicano y las élites económicas se preocuparon por impulsar las actividades artesanales del país teniendo como base la explotación intensiva de las riquezas naturales del territorio patrio y la disminución de la importación de materias primas del extranjero. Tercero, el apoyo a los productos nacionales en la feroz competencia que se estableció contra las importaciones en busca de acaparar el mercado mexicano ${ }^{32}$.

A partir de 1821 las aduanas mexicanas abrieron las puertas a gran número de productos importados que alcanzaron popularidad entre las distintas clases sociales, especialmente los textiles. La competencia económica entre productores nacionales y extranjeros se vivió como nunca antes. Entre los objetos más solicitados por el mercado mexicano se encontraban tejidos de lino, bisutería y lencería prusiana; muebles, mantas de algodón y lana de Gran Bretaña; procedentes de Francia había artículos de seda, de la industria siderúrgica, pieles, telas blanqueadas y teñidas, tanto de lino como de cáñamo, sombreros, artículos de lujo para damas y herramientas; muebles, textiles y artículos de hierro de Estados Unidos; y vinos, conservas, artículos de piel y aceites de España ${ }^{33}$.

Cuando se analizan los artículos publicados en las revistas dirigidas a los artesanos mexicanos y se aprecia la demanda de dichos productos en el país, se revela el objetivo de los redactores: mejorar la producción local de los artículos demandados con materias primas nacionales o aclimatadas en los talleres artesanales de la República Mexicana. Lo anterior sólo podía lograrse si los dueños y trabajadores del sector artesanal se ponían al tanto de las novedades científico-técnicas que aprovechaban los competidores. Ante ello, las revistas fueron consideradas el medio propicio para paliar el atraso y generar un amplio capital cultural en las diversas actividades artesanales.

En todas las revistas se efectuó un llamado a los hombres instruidos del país para que enviaran artículos divulgativos de diversas ciencias dirigidos a los artesanos, pues sólo ellos conocían las cuestiones "intimas" de la práctica científica. Entre los letrados que respondieron a esta convocatoria se encuentra el presbítero Mucio Val-

31 AnÓnImo, 1844, p. 1.

32 Bernecker, 2006, p. 109.

33 Ibídem, p. 123. 
dovinos, miembro de la Academia Mexicana de la Lengua y de la Sociedad Promovedora de Mejoras Materiales. Éste publicó en 1852 el artículo "Industria" en las páginas de la revista de esta última y expresó que en la República Mexicana hacía falta la instrucción que con tanto ánimo se había generalizado entre los artesanos de Europa $^{34}$. Lo anterior era la base sobre la cual se habían reunido varios hombres de ciencia para fomentar la economía nacional y la divulgación de las ciencias entre los artesanos.

Otro de los hombres de ciencia más distinguidos que participó en las revistas fue el eminente naturalista Pío Bustamante y Rocha. Éste publicó el "Discurso de Botánica en la apertura de esta ciencia en el Seminario Nacional de Minería el día 22 de Mayo de 1848" en El Eco del Comercio. En uno de los apartados en que se definió la Botánica y su quehacer, se enfatizó la aplicación de dicha ciencia en las manufacturas, ya que los artesanos debían instruirse en cuestiones silvícolas, para que en la carpintería se aprovechara

la dirección que artificialmente se da a la madera para reunir la solidez a la hermosura de sus artefactos; el tintorero encontrará en la analogía de las especies los medios de extender los recursos de su arte, [cuando conozca] científicamente esa multitud de plantas que producen diversos colores, como la gualda, el añil, la rubia. Otro tanto podría decirse del perfumero, del destilador y de otras profesiones fundadas en el empleo de las plantas; y aunque es cierto que en estos diferentes ramos no se necesita un conocimiento general de la Botánica, siempre será muy ventajoso que los que se dedican a ellos sepan lo bastante para no confundir una planta con otra, dedicándose particularmente a distinguir las especies relativas a su ejercicio ${ }^{35}$.

Lo mismo se podría sugerir a otro tipo de artesanos como hilanderos, orfebres, sombrereros, impresores, curtidores, cigarreros, confiteros, relojeros, cereros, ladrilleros, encuadernadores, botoneros, ensayadores, jaboneros, licoreros, joyeros, entre muchos otros. Como se aprecia, la historia natural tenía mucho que aportar a los grupos de artesanos a través de las aplicaciones prácticas, pues todos los objetos que producían tenían como base algún espécimen de los tres reinos naturales. A través de ambos escritos se observa las intenciones que tuvieron varios hombres de letras y ciencia del país por divulgar la Historia natural entre un público distante a su práctica ortodoxa, pero no por ello ajeno a la utilidad laboral o a cuestiones mundanas como el comercio de ropa, utensilios de cocina o artículos de lujo.

En El Heraldo..., el autor de "Riquezas naturales" también expresó la necesidad de que los artesanos mexicanos cultivaran la historia natural, en los distintos ramos como la Botánica, para que aprovecharan las innumerables plantas esparcidas por todo el territorio patrio. De éstas se obtendrían inmensas ventajas para las manufacturas, el comercio, la Medicina y los objetos necesarios en la vida diaria. También se estimaba necesario que se profundizaran los estudios botánicos para aclimatar plantas extranjeras de las cuales se conseguirían diversos bálsamos y resinas medicinales, exquisitas gomas, bellas maderas, valiosos aceites y nutritivas féculas, en fin, una

34 Valdovinos, 1852, p. 90.

35 Bustamante - Rocha, 1848, p. 3. 
gama de especies vegetales útiles que los artesanos bien instruidos podrían comercializar en México ${ }^{36}$. Precisamente en la década de 1840 tuvieron lugar las tentativas más importantes por ampliar la diversidad de manufacturas nacionales a través de la aclimatación de plantas.

\section{LA HISTORIA NATURAL Y SU APLICACIÓN ARTESANAL}

Entre los numerosos artículos que se propusieron enseñar a los artesanos mexicanos los diversos usos de la historia natural se expondrá una muestra representativa de los 128 artículos hallados en las revistas señaladas.

En el caso de la utilidad de las plantas resalta el escrito titulado "Del cultivo del lino y el cáñamo" del autor cuyas siglas fueron A. C. Éste recomendó que los lectores aprovecharan ventajosamente el cultivo nacional de materias primas mexicanas o extranjeras dedicadas a elaborar hilazas vegetales altamente demandadas en todos los poblados del país. Entre éstas destacaban ambas especies que en Europa se consideraban de gran valor en los ramos textiles, concretamente en la fabricación de ropa para ambos sexos, cuyos productos habían llegado a la República Mexicana desde la década de $1830^{37}$. Acerca del lino, el autor explicó a los lectores que el nombre científico era Linum usitatissimum o Petandria pentagynia, se le consideraba una pequeña planta anual que se cultivaba en varios países de Europa y que ya se había aclimatado favorablemente en México, por lo que los productos derivados de ésta resultaban de menor costo que los importados.

El interés que los artesanos debían tener por el lino residía en los tallos fibrosos, con los cuales se fabricaba hilo y tejidos muy finos. También las semillas servían para muchos fines económicos y medicinales, pues contenían un aceite craso y secante, empleado entre los productores de tintes y pinturas. Dicho aceite se extraía de la pepita interior, mientras que el tegumento era rico en mucílago que, disuelto en agua, era espeso y viscoso que extendiéndose como la clara del huevo prometía ventajas para los artesanos ${ }^{38}$. La demanda de todos estos beneficios comerciales ya era explotada por los extranjeros que sabían cómo aprovechar las diferentes partes del lino. Sin embargo, el genio mexicano mediante la divulgación naturalista podría fácilmente ponerse a la par de sus rivales y vender los mismos aceites e hilos.

Finalmente, A. C. expresó que tenía noticias de que en Europa el lino era demandado por varios laboratorios químicos que lo mezclaban con diversas harinas para hacer una masa altamente efectiva con la cual se recubrían las diversas piezas de los aparatos químicos usados en la destilación de líquidos, pues así se impedían las evaporaciones etéreas y alcohólicas que se perdían en el ambiente ${ }^{39}$. La explicación de todas estas utilidades del lino mediante ejemplos concretos basados en la experiencia

36 ANÓNIMO, 1855, p. 2. Otros escritos similares son "La Instrucción de los trabajadores" y "Economía Rural" publicados en el Semanario de la Industria Megicana...; "Educación de los artesanos" en El Heraldo...; y “¿En qué consiste la educación?” en La Imitación...

37 A. C., 1845, p. 102.

38 Ibídem, p. 102.

39 Ibídem, p. 104. 
extranjera debió alentar a varios de los lectores a probar cuál de ellas eran susceptibles de aplicarse en el taller con el fin de obtener mayores ganancias económicas, siempre y cuando siguieran paso a paso las recomendaciones publicadas ${ }^{40}$.

En el mismo sentido, los redactores de la Revista Mensual... ofrecieron a los artesanos la traducción del Tratado de la destilación del aguardiente, para que tuvieran a su alcance un libro completo de dicha arte mediante varias entregas periódicas y un precio asequible a su economía a través de la revista, para "guiar al destilador en todas su operaciones". A los lectores se les recomendaban algunas especies vegetales con las cuales podrían elaborar bebidas alcohólicas de gran demanda comercial. Por ejemplo, la uva o Vitis vinifera era el fruto más recomendado por su "naturaleza" apropiada para la producción de alcohol. Esto se explicaba porque contenía el azúcar suficiente para que una vez exprimido el jugo y al cabo de cierto tiempo se transformaba en sustancia alcohólica mediante la fermentación. Otra especie útil al artesano era la caña de azúcar o Saccharum officinarum, puesto se consideraba la única planta consumible por el hombre que lo abastecía de sustancias dulces. Igualmente con ella se producían bebidas alcohólicas y golosinas ${ }^{41}$. Dichos licores eran vendidos ampliamente por los comerciantes españoles, pero si los mexicanos aprendían los "secretos" de las plantas y el "arte" de la destilación, podrían competir en mejores circunstancias en el mercado.

Las entregas del mencionado Tratado... tuvieron como objetivo acercar el conocimiento contenido en libros, lejos de la economía de muchos artesanos, y allegárselos mediante la revista. Dicho conocimiento debía estimularlos, específicamente a aquellos vinculados con ciertos procesos químicos para que consideraran ampliar sus opciones de venta de bebidas alcohólicas, ya que en ciertos estratos de la sociedad mexicana comenzaban a estar de moda. En efecto, la Química y la Historia natural fueron ciencias que se conjugaron para instruir informalmente a los grupos artesanales en pro de su beneficio económico mediante el compromiso que los letrados establecieron con los empresarios bajo el auspicio de la revista perteneciente a la Sociedad Promovedora de Mejoras Materiales ${ }^{42}$.

En el Semanario de la Industria Megicana ... se publicó "Cera" a manera de invitación a los lectores para aprovechar un producto natural que se podía obtener fácilmente de las abejas. Tal sustancia, desconocida para algunos artesanos, especialmente los del norte del país, fue definida como un líquido producido por dichos insectos que se almacena en los alveolos del nido o colmena. La composición de ésta aún era un "misterio de la naturaleza", pero algunos estudios químicos y zoológicos demostraban que la consistencia se debía al polen de las flores que era recogido por las abejas en la libación diaria y que se transformaba en una masa dentro de los estómagos. Aunque gracias a los experimentos de Duchet de Hunter era sabido que la cera era

40 Otros ejemplos presentes en el Semanario Artístico... fueron "Mudarina vegetal" y "Lino"; y en la Revista Mensual... se publicó "El árbol de la leche”.

41 ANÓnimo, 1852, pp. 435-436.

42 Otros artículos botánicos fueron "Cultivo del añil" publicado en El Cometa ... y "Achiote", "Cereales" y "Algodonal" incluidos en el Semanario de la Industria Megicana... Todos ellos estuvieron encaminados a aprovechar las especies mexicanas en la elaboración de hilos, colorantes, cuerdas o telas que demandaba el mercado nacional. 
un azúcar semejante a la miel. Además, los químicos europeos la consideraban un aceite vegetal muy oxigenado, mezclado con una pequeña cantidad de extracto. "Ella suministra para la destilación del ácido benzoico un aceite espeso, gas hidrógeno, ácido carbónico y carbón" ${ }^{43}$.

Para el autor, los lectores que estuvieran interesados en el aprovechamiento de la cera debían instruirse en la anatomía de la abeja, el ciclo de vida, tipos de especies, diferenciación sexual, hábitos e intoxicaciones por los piquetes. Asimismo, era imprescindible que reconocieran los tipos de panales, la consistencia y color de la cera, las características físico-químicas y la manera de aprovecharla manualmente. Sin este conocimiento previo los artesanos irían "a tientas como los ciegos" que carecen del sentido de la vista para trabajar ${ }^{44}$. Este tipo de escritos alentó a ciertos lectores a buscar nuevos espacios laborales aprovechando los recursos entomológicos del país, pues los productos cereros se encontraban bien posicionados en el mercado mexicano y muchos de éstos provenían del extranjero.

Otro escrito de tinte zoológico fue "De la manufactura de las astas de los animales". Éste se interesó por explicar a los artesanos que los numerosos cuadrúpedos que portaban cornamenta en las testas se aprovechaban en varias partes del mundo para la elaboración de llamativos productos. El autor mencionó las especies animales más conocidas en México, como bueyes, vacas, cabras, venados, toros y carneros de los que anualmente se consumía la carne, pero se desperdiciaban los cuernos. Éstos estaban formados por una sustancia semitransparente capaz de ser cortada y tallarse hasta darle distintas formas dependiendo del ingenio del artesano.

Entre los objetos que se vendían bien en España, Cuba, Italia y otras regiones del mundo estaban agujas, cajas, mangos de espadas y pistolas, esculturas, peines, botones, muñecos, utensilios de cocina, plumas, cuernos para pólvora y hasta objetos de lujo femenino. El conocimiento zoológico le proporcionaría al artesano la "inteligencia" para distinguir los tipos de cuernos que se vendían en los mercados; la edad del individuo del que provenía; la maleabilidad, color, dureza y resistencia a la talla; y "el pulimento y modo de hacer grandes láminas acomodadas a las circunstancias de

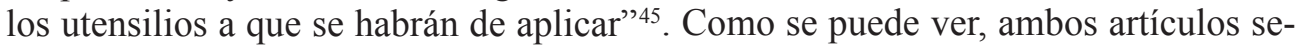
ñalaron la importancia de la Zoología como ciencia útil entre las artes sin adentrarse en el terreno fisiológico, taxonómico o anatómico, pues señalaron aquellas especies conocidas popularmente resultaban idóneas como materia prima para la manufactura de nuevos objetos destinados a los mercados nacionales.

La divulgación de la historia natural también incluyó a la Mineralogía, pues constituía un conocimiento indispensable para la fabricación de objetos de la época. Dentro de la gama de minerales útiles para los artesanos se escribieron artículos que trataron del plomo, zinc, cobre y hierro, a la par que en los años 1840-1855 se llevaron a cabo diversos reconocimientos científicos que revelaron su presencia en varias regiones del país como lo atestiguó el Catálogo de la colección mineralógica de este Museo Nacional elaborado por Antonio del Castillo renombrado catedrático del Colegio Na-

43 AnÓnimo, 1841a, p. 139.

44 Ibídem, p. 140.

45 Anónimo, 1842, p. 3. 
cional de Minería ${ }^{46}$. Ejemplo de la popularización de la práctica mineralógica entre los artesanos mexicanos fue el artículo titulado "Mineralogía" que brindó un amplio panorama sobre las virtudes de rocas y metales que se hallaban en las entrañas mexicanas. El anónimo autor inició su exposición señalando que

la Mineralogía es una ciencia que exige vasta colección de conocimiento teóricos y prácticos, que la vida de un hombre es apenas suficiente para adquirirlos. Sin embargo, los minerales son tan útiles por sus innumerables aplicaciones a los usos industriales y domésticos, que los hombres laboriosos e inteligentes que desean sacar partido de los poderosos recursos que les ofrece esta parte de la Creación necesitan algunas ideas correctas y seguras que los guíen en la elección y discernimiento de las primeras materias $[. .$.$] Bueno es que estudien y profundicen los sabios los grandes arcanos de$ la naturaleza, y que por medio de observaciones continuas y experiencias costosas lleguen a la averiguación de sus leyes; más no todos pueden ni deben elevarse a tanta altura, y la gran mayoría de la especie humana necesita más bien de ideas exactas que de meditaciones profundas ${ }^{47}$.

Esas "ideas correctas y seguras" provendrían de un mentor que bien podría estar en la misma ciudad que el lector, ser su compatriota o vivir en otro continente y hablar una lengua distinta. Esto último no significaba un contratiempo, ya que la revista fungía como el medio idóneo para establecer un vínculo docente-estudiante, aún de forma informal. Igualmente, ese docente anónimo también se había comprometido a exponer las "ideas exactas" en términos mineralógicos para no aburrir y mucho menos desorientar a los artesanos que compraran la revista, pues estaba consciente de las necesidades prácticas de todo trabajador.

El objetivo de "Mineralogía" residió en dar a los lectores "sencillas indicaciones" para que por sí mismos identificaran los minerales de mayor utilidad a los oficios empezando por el cobre y las amplias características físico-químicas. Entre las anteriores resalta la gran maleabilidad, dureza y resistencia a los golpes y atractivo color brillante. Por ello, era un metal atractivo para todo artesanos que se dedicara a elaborar utensilios de cocina, armas, instrumentos de labranza, medallas, joyería, botonaduras, candelabros y hasta escultura de gran tamaño como se empezaban a ver en Europa ${ }^{48}$.

Este breve ejemplo revela el interés de los redactores porque el público artesanal estuviera al tanto del conocimiento mineralógico más moderno que pudiera aprovechar en sus horas de trabajo. Además, creyeron importante darles un panorama de los diversos metales con los que contaba el país para fabricar cientos de objetos diferentes para el mercado nacional.

Los artesanos, en tanto que lectores, tendrían un mayor conocimiento naturalista de las plantas, animales y minerales útiles a las actividades laborales que se traduciría en una mejor explotación de todos éstos y la consiguiente prosperidad económica en lo

46 Del Castillo, 1852, p. 3.

47 ANÓNImo, 1841b, p. 261.

48 Ibídem, p. 265. Otros artículos mineralógicos son "Carbón de piedra", publicado en el Semanario de la Industria Megicana...; "Del fierro, sus usos y propiedades" en las páginas del Semanario Artístico...; y "Los minerales preciosos" en la Revista Mensual... 
individual y colectivo. Los distintos redactores de las revistas con temas artesanales publicadas entre 1840 y 1855 determinaron lentamente un tipo de lector al cual creían conveniente instruir en Historia natural que le fueran útiles en su labor diaria, misma que redundaría en el progreso de la nación. Sin duda una investigación pendiente es

registrar con precisión el comportamiento del lector [artesano], averiguar cómo es modulado este comportamiento por preferencias basadas en disposiciones de tipo anímico, social o cultural, y también cómo va cambiando [su] comportamiento [...] La gran dificultad subyace en elaborar un tamiz de investigación adecuado, que sea apto tanto para textos de las más diferentes peculiaridades como para receptores con individualidad y pasado intelectual muy variados [...] y recopilar sistemáticamente y evaluar todos los indicios que puedan conseguirse: comentarios sobre experiencias de lectura de libros, cartas o conversaciones documentadas; huellas de experiencias de lectura en la producción literaria o en el comportamiento de los lectores [...] El problema radica en que estos materiales son las más de las veces testimonios aislados ${ }^{49}$.

De momento el énfasis de esta investigación se encuentra en los contenidos y sus posibles usos entre el artesanado, aunque se vislumbran fuentes que permiten adentrarse en el lector artesano, como son las novelas de la primera mitad del siglo XIX, la literatura de viaje, memorias de mexicanos y algunas obras clásicas como Los mexicanos pintados por sí mismos (1854). Asimismo, estas páginas servirán para una reflexión futura acerca de la recepción de los escritos naturalistas entre los artesanos mexicanos, sus mecanismos y complejidad.

\section{CONSIDERACIONES FINALES}

La práctica de la historia natural tuvo amplio espacio en las revistas mexicanas para artesanos de la primera mitad del siglo XIX a tono con las publicaciones de otras partes del mundo. Lo anterior se debió a que éstas jugaron un papel fundamental en la instrucción informal de los lectores, pues como se mencionó en la introducción, fue hasta 1856 que se fundó la Escuela de Artes y Oficios en la capital del país ${ }^{50}$. Presumiblemente, la inclusión de la divulgación naturalista en esta prensa estuvo motivada por el interés de los hombres de letras y ciencia por ampliar los límites de la cultura científica para que acogiera a la mayor cantidad de grupos sociales.

El asociacionismo culto, como el desarrollado en la ciudad de México, fue un factor significativo en la promoción de las mejoras científico-técnicas encaminadas a los sectores productivos del país, pues en éstas se reunieron hombres interesados en el fomento económico nacional. Las revistas analizadas se convirtieron en voceros de las aspiraciones educativas, sociales, políticas y comerciales, junto con el establecimiento de un ambiente propicio para la revaloración de las actividades artesanales a partir de su vinculación con la ciencia. Además, los letrados se erigieron como el

49 Maurer, 1987, pp. 248-250.

50 Algunos escritos referentes a este tema son "Escuela de Agricultura" publicado en el Semanario de la Industria Megicana...; y "Proyecto para establecer un el Estado de Jalisco una Escuela de Agricultura" dentro de la Revista Mensual... 
cuerpo cultural que decidía acerca de los conocimientos a divulgar, las estrategias utilizadas y los objetivos que debían alcanzarse en las revistas para artesanos de manera unidireccional, es decir, sin tomar en cuenta su opinión.

El vínculo que se intentó establecer entre naturalistas, letrados y artesanos tuvo como finalidad la explotación de las riquezas naturales de la república, no sólo para la venta al extranjero, sino la transformación en productos que demandaba la sociedad del país. Todo ello redundaría en una posible bonanza económica que beneficiaría a todos los grupos sociales, pues el mercado comercial era considerable.

En los diversos contenidos naturalistas que tal vez atraparon la mirada de los artesanos, resultan perceptibles las finalidades que los autores buscaron: mejorar la elaboración de objetos tradicionales para su comercialización y la innovación de éstos a través de nuevas materias primas en el contexto de una feroz pugna entre nacionales y extranjeros por acaparar el mercado mexicano. Para lograr ambos objetivos se publicaron escritos que brindaron elementos científicos para mejorar la producción artesanal. Igualmente se incluyeron artículos que los alentaron a conocer nuevas materias primas, tanto de origen nacional como extranjero, como ya había sucedido con los artesanos europeos.

Las distintas sugerencias de aprovechamiento de nuevas plantas con utilidad económica publicadas en las revistas para artesanos estuvieron acorde con los proyectos de los hombres de ciencia que laboraban en espacios propios de la cultura letrada, tales como el Museo Nacional, el Jardín Botánico o el Colegio de Minería, que tuvieron por objetivo el estudio de los recursos naturales del país, especialmente aquellos considerados materias primas exportables a Europa en grandes cantidades. Esta relación entre las instituciones científicas y la divulgación del conocimiento que ahí se generaba durante el siglo XIX está pendiente de estudio.

En cuanto a la transmisión de saberes naturalistas, propios de la cultura letrada, en las revistas destinadas al ambiente artesanal se contó con dos grupos interesados en ello. Uno, formado por redactores y articulistas que consideraron viable destinar parte de su tiempo y dinero a tal empresa, pues se habían erigido a sí mismos como "sabios educadores" del pueblo. Otro estuvo constituido por los trabajadores y dueños de talleres que se preocuparon por adquirir las revistas destinadas a ellos y estimaban que los distintos contenidos ampliarían su bagaje cultural. Esto tendría una utilidad en su quehacer laboral frente a la venta de productos importados, independientemente de su jerarquía dentro del gremio artesanal.

Si bien en esta investigación sólo se nombraron dos articulistas proveniente del ámbito letrado como Mucio Valdovinos y Pío Bustamante y Rocha, no estuvieron solos en su cruzada por llevar el conocimiento culto hacia los artesanos, como lo demuestra la activa participación de Juan N. Almonte, Manuel Larrainzar, José Joaquín Pesado y Miguel Lerdo de Tejada en la Revista Mensual...; y Manuel Payno, Félix María Escalante, Pablo J. Villaseñor, Antonio del Río, Anselmo de la Portilla y Luis Manuel del Rivero en El Eco del Comercio. Todos ellos instruyeron a los artesanos desde varias ámbitos, como la Historia, Política, Moral y Literatura, entre otros temas, que junto con las disciplinas científicas "elevarían" la situación social de los lectores en cuestión. 
No hay que dejar de lado que gracias al esfuerzo de redactores y articulistas, los artesanos pudieron tener a su alcance un conocimiento homogéneo acerca de las ventajas de la instrucción científica, en este caso naturalista. En efecto, si las revistas llegaban a talleres de la ciudad de México, Puebla, Guadalajara, Querétaro, Oaxaca o Zacatecas, los lectores tendrían el mismo capital científico y cultural dispuesto para la aplicación en sus labores a pesar de las distancias que separaban a unos de otros, junto con la pluralidad de edades y experiencia.

La constancia de la prensa para artesanos en los años 1840-1855 se debió al interés de redactores y articulistas que se sumó al interés de varios lectores que consideraron a la divulgación del conocimiento naturalista como motor de sus actividades laborales y posiblemente creyeron que si estaban instruidos en esta ciencia desempeñarían mejor las tareas y al aplicarlo resultarían más productivas sus "manos". Para ello, fue necesario introducir a estos lectores en la terminología académica, propia de la historia natural, pero de una forma sencilla y amena. De esta manera, las revistas constituyeron el vínculo más estrecho entre la cultura letrada del país y los gremios artesanales.

Finalmente, la instrucción naturalista de tinte informal con fines artesanales se centró en aquellos conocimientos que los lectores podrían practicar in situ, es decir, en los lugares habituales de trabajo. Esto se debió a la falta de instituciones educativas en todo el país que normaran los estudios de los artesanos. Asimismo, el conocimiento naturalista se convertía en un capital cultural susceptible de aplicación a lo largo de la vida laboral del lector y que podía transmitir de manera oral o impresa al prestar la revista a otros artesanos interesados, hijos y aprendices. La transmisión de saberes letrados no sólo beneficiaba a una generación de lectores, sino que ampliaba su grado de influencia a lo largo del tiempo, pues el conocimiento científico impreso no caducaba rápidamente. No obstante, aún hace falta adentrarse a la recepción de los escritos naturalistas. Sin embargo, es factible considerar que mediante las páginas de estas revistas numerosos artesanos debieron leer, ya fuera en sus hogares, en los talleres, en los descansos de las faenas laborales o en reuniones en espacios públicos, las distintas plumas que intentaron instruirlos en cuestiones prácticas de la historia natural aplicada a su día a día.

\section{REFERENCIAS BIBLIOGRAFICAS}

A. C.

1845 "Del cultivo del lino y el cáñamo". Semanario Artístico para la Educación y el Progreso de los Artesanos. México, vol. I, pp. 102-106.

Agulhon, Maurice

1994 Historia vagabunda. Etnología y política en la Francia contemporánea. México. Instituto de Investigaciones Dr. José María Luis Mora.

ANÓNIMO

1841a "Cera». Semanario de la Industria Megicana que se Publica Bajo la Protección de la Junta de Industria de esta Capital. México, vol. I, pp. 139143. 
1841b "Mineralogía". Semanario de la Industria Megicana que se Publica Bajo la Protección de la Junta de Industria de esta Capital. México, Vol. I, pp. 261-271.

1842 "De la manufactura de las astas de los animales". El Cometa. Semanario de Política, Agricultura y Artes. México, vol. I, p. 3.

1844 "Educación literaria". Semanario Artístico para la Educación y el Progreso de los Artesanos. México, vol. I, pp. 1-2.

1852 "Tratado de la destilación del aguardiente. Obra dedicada a los destiladores mexicanos, traducida y compendiada por J. F. S., con ocho láminas que representan los principales alambiques y aparatos del destilador". Revista Mensual de la Sociedad Promovedora de Mejoras Materiales. México, vol. I, pp. 385-472.

1855 "Riquezas naturales". El Heraldo. Periódico Político, Industrial, Agrícola, Mercantil, de Literatura y Artes. México, vol. II, p. 2.

Azuela, Luz Fernanda - Vega y Ortega, Rodrigo

2011 "La ciudad de México como capital científica de la nación (1760-1910)". En LÉRTORA, (coord.), Geografía e Historia Natural: hacia una historia comparada. Estudio a través de Argentina, México, Costa Rica y Paraguay. Tomo IV. Buenos Aires. FEPAI, pp. 51-90.

BERNECKER, Walther

1999 "Industria versus comercio: ¿orientación hacia el interior o hacia el exterior?". En GómeZ-GaLVARRiato (coord.), La industria textil en México. México. UNAM - El Colegio de Michoacán - El Colegio de México - Instituto de Investigaciones Dr. José María Luis Mora, pp. 114-141.

2006 "Competencia comercial europea a través del Atlántico: el caso de México, siglo XIX". En Kuntz - Pietschmann (eds.). México y la economía atlántica (siglos XVIII-XX). México. El Colegio de México, pp. 109-142.

Bustamante y Rocha, Pío

1848 "Discurso de Botánica en la apertura de esta ciencia en el Seminario Nacional de Minería el día 22 de Mayo de 1848". El Eco del Comercio. Periódico de Literatura, Política, Artes e Industria de la Sociedad Filantrópica Mexicana. México, vol. II, pp. 2-3.

CÁRDENAS, Enrique

1999 "Una interpretación macroeconómica del México del siglo XIX". En HABER (comp.), Cómo se rezagó la América Latina. Ensayos sobre las historias económicas de Brasil y México, 1800-1914. México. Fondo de Cultura Económica, pp. 83-114.

Connaughton, Brian

2003 Poder y legitimidad en México en el siglo XIX. Instituciones y cultura política. México. Universidad Autónoma Metropolitana - CONACYT - Miguel Ángel Porrúa.

2006 "Voces europeas en la temprana labor editorial mexicana 1820-1860". Historia Mexicana. México, vol. LV, n³, pp. 895-946. 
COROnA, Leonel

2004 La tecnología, siglo XVI al XX. México. UNAM - Océano.

Del Castillo, Antonio

1852 Catálogo de la colección mineralógica de este Museo Nacional, arreglada por el profesor del ramo, catedrático del Colegio Nacional de Minería, D. Antonio del Castillo, conforme al sistema mineral del Sr. Barón de Bercelio. México. Imprenta de Vicente García Torres.

Fyfe, Aileen - Ligthman, Bernard (eds.)

2007 Science in the Market place. Nineteenth-Century Sites and Experiences. Chicago. The University of Chicago Press.

García Luna, Alejandro - Morelos, Lucero

2011 "La Geografía y la Mineralogía en El Minero Mexicano (1873-1879)". En LÉRTORA (coord.), Geografia e Historia Natural: hacia una historia comparada. Estudio a través de Argentina, México, Costa Rica y Paraguay. Tomo IV. Buenos Aires. FEPAI, pp. 225-258.

GonzÁLEZ, Sofía

2010 "Cientificos pero también religiosos": El Abogado Cristiano Ilustrado, periódico de la Iglesia Metodista Episcopal de México (1880-1910). México. La autora. Tesis de Licenciatura en Historia. UNAM.

GueVARA, Rafael

2009 "En busca de la tradición científica del México independiente: una cita, un cuento y un gráfico". En Velasco (coord.), Humanismo novohispano, Independencia y liberalismo. México. UNAM, pp. 245-274.

ILlades, Carlos

2004 "Las revistas literarias y la recepción de las ideas en el siglo XIX". Historias. México. n57, pp. 51-63.

JARDINE, Nick - SECORD, James - SPARY, Emma (eds.)

2000 Cultures of Natural History. Cambridge. Cambridge University Press.

KNIGHT, Charles

2007 Passages from a Working Life During Half a Century. With a Prelude of Early Reminiscences. Chicago. The University of Chicago Press.

Lyons, Martin

2006 "Los nuevos lectores del siglo XIX: mujeres, niños, obreros". En CAVALLO - Chartier (eds.), Historia de la lectura en el mundo occidental. México. Taurus, pp. 478- 521.

MAURER, Karl

1987 "Formas de leer". En Mayoral (comp.), Estética de la recepción. Madrid. Arco Libros, pp. 245-279.

Negrín, Olegario

2009 "La educación popular de la Real Sociedad Económica Matritense: ¿formación profesional o trabajo artesanal?". En AstiRRAGA - LÓPEZ-CORDÓN - URKIA (eds.), Ilustración, ilustraciones. San Sebastián. Tomo I. Real Sociedad Bascongada de los Amigos del País, pp. 433-452. 
ORDÓÑEZ, Javier - ElenA, Alberto (coords.)

1990 La ciencia y su público. Madrid. Consejo Superior de Investigaciones Científicas.

Ortiz Monasterio, José

2005 "La revolución de la lectura durante el siglo XIX en México". Historias. México, $n^{\circ} 60$, pp. 57-75.

Pérez Toledo, Sonia

1996 Los hijos del trabajo. Los artesanos de la ciudad de México, 1780-1853. México. Universidad Autónoma Metropolitana - El Colegio de México.

2003 "Entre el discurso y la coacción. Las élites y las clases populares a mediados del siglo XIX". En Connaughton (coord.), Poder y legitimidad en México en el siglo XIX. Instituciones y cultura política. México. Universidad Autónoma Metropolitana - CONACYT - Miguel Ángel Porrúa, pp. 311-338.

2004 Población y estructura social de la ciudad de México, 1790-1842. México. Universidad Autónoma Metropolitana - CONACYT.

Plana, Manuel

2004 Las industrias, siglos XVI al XX. México. UNAM - Océano.

Redactores

1842 "Prospecto". El Cometa. Semanario de Política, Agricultura y Artes. México, Vol. I, p. 1.

1850 "Introducción". La Imitación. Periódico de Literatura, Bellas Letras y Artes. México, vol. I, p. 2.

1853 "Prospecto". El Artista. México, vol. I, p. 1.

SÁnchez García, Raquel - Martínez, Ana

2010 La lectura en la España contemporánea. Madrid. Arco Libros.

SAntos, Isnardo - GonzÁlez, Carlos

2005 "Usos, formas y contexto de la prensa destinada a los trabajadores en la ciudad de México en el siglo XIX”. En Clark- Speckman (eds.), La república de las letras. Asomos a la cultura escrita del México decimonónico. Tomo III. México. UNAM, pp. 159-170.

SuÁREZ, Laura

2005 "Los impresos: construcción de una comunidad cultural. México, 18001855 ”. Historias. México, nº60, pp. 77-92.

TrujILlo, Mario

1997 Operarios fabriles en el valle de México, 1864-1884. México. El Colegio de México - Centro de Investigaciones y Estudios Superiores en Antropología Social.

VALDOVINOS, Mucio

1852 "Industria". Revista Mensual de la Sociedad Promovedora de Mejoras Materiales. México, vol. I, p. 90. 
Vodicka, Felix

1989 "La estética de la recepción de las obras literarias". En W ARNING (ed.), Estética de la recepción. Madrid. Visor, pp. 55-62.

WeBB, Robert

1955 The British Working-Class reader, 1790-1848: literacy and social tension. London. Allen and Unwin. 